\title{
Preference and Behavior
}

\author{
A Response to Buss
}

Robert W. Smuts

Evolution and Human Behavior Program, University of Michigan, Ann Arbor, Michigan

$\mathbf{M}$

uch of the apparent disagreement between Buss $(1989,1991)$ and me $(1989,1991)$ arose from some lack of clarity and precision on both sides, particularly with respect to the distinction between "preference" and "behavior." We now understand each other much better than we did.

In animal studies, mating preference is identified and measured on the basis of behavior. In Buss's studies, preference is identified and measured on the basis of what people say they want, not what they do. In commenting on his 1989 article, I concluded that Buss was using his measures of speciestypical mate preference as at least a rough approximation of actual mate choice behavior. He has now (1991) made it unmistakably clear, however, that he is using "preference" to refer, not to a particular corresponding behavior, but to a "psychological mechanism" that, in combination with other mechanisms and with environmental influences, determines which of many possible behavioral responses an individual chooses.

I have no quarrel with that definition or with Buss's convincing and valuable demonstration that human females, wherever studied, show a preference (as so defined) for males that have or seem likely to acquire resources. I agree that this preference is very likely to have been evolved. My principal criticism of his 1989 paper was that he gave scant attention to context-dependent variation in mate choice behavior and thus appeared to minimize its importance. It is good to know that he has now turned his attention in that direction, and I look forward to seeing the results.

Received May 4, 1991; revised May 4, 1991.

Address reprint requests and correspondence: Robert W. Smuts, 4011 Thornoaks, Ann Arbor, MI 48104. 


\section{REFERENCES}

Buss, D.M. Sex differences in human mate preferences: Evolutionary hypotheses tested in 37 cultures. Behavioral and Brain Sciences 12(1): 1-14, 1989.

- Do women have evolved preferences for men with resources? A reply to Smuts. Ethology and Sociobiology 12(5): 401-408, 1991.

Smuts, R.W. Behavior depends on context. Behavioral and Brain Sciences 12(1): 33-34, 1989.

- The present also explains the past. Ethology and Sociobiology 12(2): 77-82, 1991. 